produce healthy children with close liaison between obstetric, medical, and surgical services. On the other hand, iatrogenic failures are on the increase as amniocentesi and serum $\alpha$-fetoprotein levels give false results and induce congenital abnormalities.

For those who feel they cannot cope with a child organisations such as the Society for the Protection of Unborn Children (SPUC), the Innocents, and the pro-life movements offer support. Also adoption agencies cannot meet the demands of their clients.

Surely we have a duty to protect the life of the defenceless unborn child?

ANNE M BANCEWIC

Airdrie, Lanarkshire

SIR,-Your leading article (2 February, $p$ 269) on abortion contains several extraordinary assertions which need challenging. For example, contraceptive failure is not an automatic reason for termination of pregnancy under the 1967 Abortion Act. If it eve became so we would be even further on the way to the introduction of compulsory abortion at the whim of bureaucrats (medical and otherwise), an idea which has already been suggested by the "population" lobby in the United States.

Wisbech, Cambs PE14 7EU

Elizabeth ElliotT

SIR,-Mr John Corrie misunderstands my letter of 26 January (p 248) in his letter of February ( $p$ 329). The words "serious" and "substantial" do not appear in the subsection of the Abortion Act 1967 that permits about $98 \%$ of the abortions performed each year on British women. His proposal to insert these words must increase the problems experienced by those with unwanted pregnancy. The word do, of course, appear elsewhere in the 1967 Act in relation to other reasons for abortion.

$\mathrm{He}$ is right to believe that I fear that clause 4 of his Bill will make legal abortion difficult to obtain outside the National Health Service. He says that this ill-judged and ill-drafted clause is necessary to prevent fee splitting. The Secretary of State already has wide powers to regulate the provision of private abortion and would undoubtedly take action if there was evidence that women were being exploited or that the law was being broken.

Department of Obstetrics and Gynaecology,

St Marys Hospital Medical School,

D B Paintin

SIR,-How right you were to emphasise the principle of clinical judgment in your leading article (2 February, p 269), thus finding common ground with the majority of the profession, so unhappily divided by the legislation on this subject.

There is no doubt in my mind, that, whatever legislation finally emerges, in the event of conflict between my own clinical judgment and the law on the Statute Book I would not hesitate to choose the former.

I think we are beginning to appreciate how impossible it is to legislate for human behaviour, especially on the subjects of life and death, for which the doctor-patient relationship uniquely exists.

Cirencester, Glos GL7 2ER

J C MILLER

SIR,-When all is said and done the most important argument against $\mathrm{Mr}$ John Corrie's Abortion (Amendment) Bill must be that it is based on a misunderstanding of the problem. All the evidence points to the conclusion that it is not possible to prevent abortion by legislation. Countries with restrictive legislation often have high abortion rates, one in every two or three pregnancies being terminated in conditions which result in considerable loss of life and damage to health.

It was a recognition of this fact which persuaded many people of the necessity for liberal Act in 1967 and nothing has changed to alter the supposition that a large proportion of women denied legal abortion will seek an illegal one. The major medical establishment bodies recognise and accept this and are opposed to the Corrie Bill.

It is apparent to those of us working in this field and from the findings of recent studies in Wessex that what is really needed is a much greater effort in providing sex education and access to contraceptive advice and methods for those with special problems-namely younger and older women and women who ar unable to use oral contraceptives. An irony of the proposed legislation is that abortion rate have until very recently been falling, following the major expansion of family planning provision in 1974. There is no evidence that women are using abortion as a substitute for contraception and the increase in abortion rates in 1978 has probably a lot to do both with the impact of the economic recession on couples struggling to put a home together and with the major pill scare in 1977.

A great deal of paper has been used in the current debate on the effects of lowering the accepted limit for abortion to 20 weeks. In my view this measure would only add to the anguish and difficulties of women and doctor in the very small proportion of cases involved and it is difficult to see why the Lane Com mittee's recommendation of 24 weeks canno be accepted as a compromise.

The introduction of the words "grave" and "substantial" into the concept of risk to the mother or her existing family is widely believed to be designed to intimidate doctor by the threat of legal action. So diffuse does the concept become and yet in some minds so tight that it would be almost impossible to get two lawyers to agree on the meaning of these words. The prospect for vexatious litigation is unlimited.

Of the three principal changes introduced in the Bill, however, it is the one which aims to separate counselling from operating which has by far the most important consequences. Thi measure is aimed at the two main abortio charities, the Pregnancy Advisory Service and the British Pregnancy Advisory Service, which were set up to meet the deficiencies of provision by the National Health Service and which between them account for $30-40 \%$ of abortions carried out. Throughout the cours of the debate on the Corrie Bill it has been suggested that people working for these charities have a financial interest in drumming up work. There is absolutely no evidence for this and, in fact, there is now hard evidence from the British Pregnancy Advisory Service that the counselling provided is of a neutra and non-directive kind. In a study to be published in the Fournal of Biosocial Science in July it was found that when people attending a British Pregnancy Advisory Service clinic were questioned about their experience only $18 \%$ said that the counsellor had raised the question of abortion, compared with $28 \%$ for general practitioners, $32 \%$ for mothers, and $38 \%$ for fathers. Sixty-four per cent of patients said that they had no idea what the counsellor's attitude to abortion was (GPs, $56 \%$; mothers, $24 \%$; fathers, $40 \%$ ) and only $46 \%$ said they thought that the counsellor was in favour of their having an abortion (GPs, $47 \%$; mothers, $74 \%$; fathers $72 \%$ ). These findings must be taken as strong evidence that the claims made against the charities are a fiction.

As a doctor with a responsibility for preventive medicine, I am concerned that what we are witnessing is an attempt to reverse a rational public health policy, the equivalent of which 100 years ago would have been a decision to abandon piped water.

JoHn Ashron

Department of Community Health

London School of Hygiene and Tropical Medicine, London WC1E $7 \mathrm{HT}$

\section{Legal abortion in England and Wales} 1968-78

SIR,-Mr T L T Lewis has presented a welcome review of legal abortion in England and Wales during 1968-78 (2 February, p 295). But what grounds did he have to include the sentence "It is typical of the DHSS to have acknowledged the emormous amount of extra work arising from the 1967 Act by providing no extra beds in which to do it"?

The latest available national statistics ${ }^{1}$ tell a different tale. Average available beds in England for gynaecology increased during 1966-76 from 9400 to 10400 ; and discharges and deaths rose from 380700 to 476600 . But the average length of stay fell from $7 \cdot 4$ days to 5.0 days, and so did the occupancy (the two are related)-from $84 \%$ to $69 \%$ Doctors working in the specialty of obstetrics and gynaecology increased from 1355 (wholetime equivalents) in 1963 to 1960 in 1972 and to 2176 in 1976. During this period the birth rate fell by almost $40 \%$. The statistics also show that in 1976 there were only 43400 day cases, compared with about half a million hospital discharges and deaths. (There were also 502000 outpatient attendances.)

Sterilisation, ${ }^{2}$ examination under anaesthetic, tubal insufflation, removal of cysts, ${ }^{3}$ and uterine curettage ${ }^{4}$ have been described as successful day-case procedures. The most important measure in the context of $\mathrm{Mr}$ Lewis's subject would be to increase the provision of day abortion services,,$^{5-7}$ or single-night stay if this is preferred for anaesthetic recovery. In 1977 about 40000 abortions with a gestation of 12 weeks or less were performed in NHS hospitals, and the same number in non-NHS hospitals. In the NHS only $15 \%$ of these patients were day cases and $14 \%$ stayed one night, whereas in non-NHS hospitals $27 \%$ were day cases and $69 \%$ stayed one night. ${ }^{8}$ Better use of clinica resources is a responsibility of doctors. To complain of DHSS stringency, when there is evidence of real increases and also further opportunities for efficiency, would seem to be part of the widespread misunderstanding in this country of the value of health service administration.

MARK McCarthy

\section{Department of Community Medicine}

School and Royal Free

London WC1E 6JJ

${ }^{1}$ Department of Health and Social Security. Health and personal social services statistics for England 
2 Brash JH. Br Med f 1976;1:1376-8.

3 Craig CA. Br Med $\mathcal{f}$ 1970;ii:786-7.

: Anonymous. Lancet 1979; 1 :1174.

Lewis SC, Lal S, Branch B, et al. Br Med f 1971; iv:606-10.

indell $\mathrm{K}$, Grahame $\mathrm{H}$, eds. Outpatient abortion: a symposing 1974.

McGarry J. Minimal delay outpatient termination of pregnancy. Health Trends 1977;9:7-9.

Office of Population Censuses and Surveys. Abortion statistics 1977. London: HMSO, 1979:26-7.

\section{Improvements in obstetric anaesthetic services}

SIR,-We welcome the correspondence which our article (22 September, p 698) has promoted, especially the letters from Dr D J Bowen and others (15 December, p 1587) and from Mr G Roberts and Mr P J BradleyWatson (26 January, p 251).

It is clear that there is concern about the inadequacy of obstetric anaesthetic services and we have endeavoured to stimulate awareness of these deficiencies. We believe, with your correspondents, that in ideal circumstances a full range of methods of pain relief, including epidural analgesia, should be available in every consultant unit. But this will take time and money and we were at pains to draw attention to alternative and we would hope interim measures. No medical administrator could produce logical arguments to block essential improvements in pain relief for obstetrics.

Mr Roberts and Mr Bradley-Watson comment on the uneven distribution of consultant sessions in Wales, a point which we ourselves emphasised, although we deliberately avoided specifying areas of exceptional deficiency for fear of creating public alarm. Since there are only 12 exclusive obstetric anaesthetic sessions in the whole of the principality, it is clear that their assumption that there are two wholetime obstetric anaesthetists in South Glamorgan must be incorrect. Indeed, the number of sessions allocated between the two major obstetric units in South Glamorgan is eight and this includes time spent in the training of junior staff who will ultimately supply the needs of the district general hospitals in Wales. We note with pleasure that for the first time the large unit at Carmarthen is going to have an anaesthetist with designated obstetric sessions. Perhaps our review of the services, to which Mr Roberts contributed, has played some small part in achieving this innovation.

$\mathrm{Mr}$ Roberts and $\mathrm{Mr}$ Bradley-Watson are also to be congratulated on achieving skill and experience in the administration of epidural analgesia and personally providing this facility for some of their patients. However, only a limited number of obstetricians have the necessary skills, time, and inclination and none could include within their commitments epidural analgesia for all patients who desire it. Your correspondents imply that we suggest that midwives should not be involved in "top-up" injections. This was not the case which we put. We agree that midwives should be involved providing they are trained to cope with any complications which may arise or a trained doctor is within the immediate vicinity.

\section{BRYAN HIBBARD}

M ROSEN

G A D REES

Department of Obstetrics and Gynaecology, Welsh National School of Medicine,

***This correspondence is now closed.-ED, BMF.
Treatment of infertility with levodopa

SIR,-We read with interest the paper by Dr M O Thorner and others (29 September, p 771) dealing with bromocriptine and pregnancy. Bromocriptine has been used in a variety of endocrine and neurological disorders, including hyperprolactinaemia, acromegaly, infertility, premenstrual tension, Parkinson's disease, etc, with varying degrees of success. When there is reason to suspect dopamine deficiency as the primary neurotransmitter defect, treatment with this dopaminergic agonist has generally been effective. However, because there is some theoretical concern that bromocriptine may be a teratogen we have been employing instead low doses of levodopa (a dopamine precursor) with success in the treatment of infertile women.

Since July 1975 up to the present we have treated 17 infertile patients, all of whom subsequently conceived within two months of attempted conception. All the patients were married nulliparous women (age range 34-33 years) who had been trying to conceive for four or more years. Eleven normal babies have been delivered up to the time of writing and five normal pregnancies are in progress. One spontaneous abortion occurred. All patients reported regular menstrual periods although five showed high levels of serum prolactin concentration $(27,36,42,56$, and $75 \mathrm{ng} / \mathrm{ml}$ ); two of the latter had galactorrhoea. All patients showed normal skull radiographs. In all cases organic diseases were excluded and a psychiatric diagnosis of depression was made. Hypoactivity of the dopaminergic system was established at the level of th distal colon according to a previously described procedure.

One oral daily dose of levodopa (125 mg) was administered, along with $0.3 \mathrm{mg}$ of haloperidol, from the fifth postmenstrual day until the first day of the next period. The experimental finding that high doses of levodopa reverse the induced hyperdopaminergic behaviour ${ }^{2}$ led us to employ low doses. Our broad experience in the use of levodopa in many psychosomatic illnesses has shown us that the addition of low doses of haloperidol potentiates and prolongs its dopaminergic agonistic effects. ${ }^{45}$ Low doses of butirophenones in effect block presynaptic autoreceptors preferentially, thus inducing dopamine release. In all cases the medication was interrupted as soon as the first period was missed by 15 days.

F LECHIN

Catedra de Patologia General y

Fisiopatologia,

Central University of Venezuela

1 Lechin F, van der Dijs B. f Clin Pharmacol 1979; 19:617-25.

2 Ezrin-Waters C, Seeman P. Life Sci 1978;22:1027-32. Lechin F, van der Dijs B, Lechin E. The autonomic nervous system. Physiological basis of psychosomatic therapy. Barcelona: Editorial Cientifico-Médica, Mcmilla

Mcmillan BA, Shore PA. F Pharm Pharmacol 1977;
29:780-1.
Farnebo Lo, Hamberger B. Acta Physiol Scand (suppl) $1971 ; \mathbf{3 7 1}: 35-44$

\section{Debendox and the media}

SIR,-In common with many of your readers, we were disturbed to read on the front page of the Observer on 20 January a report of impending legal action in the United States against Merrill National Laboratories, the manufacturer of Debendox (dicyclomine hydrochloride, Bendectin in the United States), an antiemetic drug widely used in pregnancy. The report appeared under the dramatic and ambiguous title "New thalidomide-style drug fear." Predictably, women now pregnant who have taken the drug have become extremely alarmed about the possible effects on their fetuses.

So far as retrospective studies in man can ever be totally convincing, the record for Debendox is good. Several surveys ${ }^{12}$ have failed to detect any increase in birth defects in the newborn in mothers who have taken Debendox, while the Department of Health and Social Security in Britain and the Food and Drug Administration in the United States have been reassuring. However, a number of anecdotal reports ${ }^{3-5}$ have involved fairly unusual combinations of malformations in fetuses exposed during the first six weeks of pregnancy. Needless to say, similar malformations have occurred in fetuses of women who did not take Debendox, while some women who did take Debendox during this early stage of pregnancy went on to produce normal children.

We now have a unique opportunity to carry out a prospective study of the effects of Debendox in pregnancy as a result of the publicity given to the drug in the popular media. Following discussions with the Medicines Division of the DHSS, it seems to us to be a good idea to ask doctors to write to us letting us know of any women who they are certain have taken Debendox during the first six weeks of pregnancy, together with precise dates and a note of their previous menstrual cycle and immediate contraceptive habits. They should then let us know the outcome of pregnancy, whether this be a normal liveborn child, a child with malformations (including details of type of malformation), or fetal death at any stage. It is essential for any adverse reactions also to be reported to the Committee on the Safety of Drugs in the usual way. We also wish to know of any factors such as exposure to other drugs or to infections which are considered to be relevant.

Although open to all sorts of objections, this will be a valuable prospective study of the effects of Debendox in the early stages of pregnancy.

RODNEY HARRIS DIAN DONNAI

Department of Medical Genetics, St Mary's Hospital,

Smithells RW, Sheppard S. Teratology 1978;17:31-6. Shapiro S, et al. Am f Obst Gyn 1977;128:480.

3 Donnai D, Harris R. Br Med

s Mellor S. Br Med 1978 ; :1055.

SIR,-Yet again pregnant women are being subjected to needless anxiety by the uninformed actions of the media. Since the reports, both in the press (as discussed in Medicine and the Media, 2 February, p 320) and on television about the alleged harmful effects of Debendox (dicyclomine hydrochloride), I have had to reassure quite a number of women attending the antenatal clinic. Those who remain anxious, and who are less than 18 weeks' pregnant, are being offered serum $\alpha$-fetoprotein estimation.

May I suggest through your columns that further cases of the unusual syndrome of fetal gastroschisis ${ }^{1}$ are reported to the Committee of Safety of Drugs with details of drug therapy 